\title{
ANALISIS POTENSI DESA DITINJAU DARI SOSIAL BUDAYA KESENIAN TRADISIONAL RONGGENG GUNUNG DALAM MENINGKATKAN PENDAPATAN MASYARAKAT PRASEJAHTERA \\ (Studi kasus di desa Ciulu Kec. Banjarsari Kab. Ciamis Jawa Barat)
}

\author{
Dewi Ratih ${ }^{\text {a }}$, Wulan Sondarika ${ }^{b}$ \\ ${ }^{a, b}$ Dosen Program Studi Pendidikan Sejarah FKIP-Universitas Galuh Ciamis \\ Jl. R. E. Martadinata No. 150 Ciamis, 46274 Jawa Barat
}

\begin{abstract}
ABSTRAK
Penelitian ini bertujuan untuk menganalisis potensi sosial budaya kesenian tradisional Ronggeng Gunung terhadap pendapatan masyarakat prasejahtera. Populasi penelitian adalah pemerintahan Desa Ciulu dan pelaku kesenian ronggeng gunung Bi Raspi dan kawan-kawan. Hasil dari penelitian ini diantaranya adalah; potensi sosial budaya kesenian tradisional Ronggeng Gunung di Desa Ciulu Kecamatan Banjarsari Kabupaten Ciamis kurang memberikan dampak baik terhadap perekonomian masyarakat terutama bagi pelaku Ronggeng Gunung itu sendiri karena tidak adanya perhatian dari pihak pemerintah.
\end{abstract}

\section{Kata Kunci: Potensi Desa, Sosial Budaya, Ronggeng Gunung}

\section{ABSTRACT}

This study aims to analyze the social potential of traditional arts culture Ronggeng Gunung to the income of the underprivileged community. The research population is the government of Ciulu Village and artist of ronggeng mountain Bi Raspi and friends. The results of this study include; cultural potential of traditional culture Ronggeng Gunung Village Ciulu Banjarsari District Ciamis less impact on the economy of the community, especially for the perpetrators of Ronggeng Mountain itself due to the lack of attention from the government.

\section{Keywords: Potential Village, Social Culture, Ronggeng Gunung}

\section{PENDAHULUAN}

Ronggeng Gunung merupakan pertunjukkan yang menampilkan seorang penari sekaligus penyanyi yang berasal dari gunung. Penyajian Ronggeng Gunung dimainkan dengan alat musik sederhana yang terdiri dari satu kendang, tiga ketuk dan satu gong. Ronggeng ini mempunyai lagu-lagu khas. Setiap lagu berpadu dengan tarian khusus dan penyajian satu lagu ini dianggap satu babak. Gerakan tari Ronggeng Gunung lebih bertumpu pada kaki. Penari biasanya menari secara bergerombolan, membentuk lingkaran yang mengelilingi ronggengnya. Pada lagu tertentu menari dengan berkerudung sarung atau iket (Dadan wildan dkk. 2005: 130).

Ronggeng Gunung juga merupakan hiburan bagi masyarakat disekitar pegunungan, disajikan sebagai hiburan pelepas lelah manakala mereka selesai menanam padi atau sehabis panen. Untuk pelepas lelah dan disajikan pada waktu malam hari (Sejarah singkat Ronggeng Gunung, 2012).

Namun selain untuk hiburan masyarakat pegunungan Ronggeng juga biasa ditampilkan dalam acara-acara penjamuan makan malam di rumah kediaman para Bupati. Beberapa gadis penari ditampilkan dan para Bupati serta Adipati menari dengan masing-masing penari dengan diiringi suara musik yaitu gamelan yang berlanjut sampai larut malam (John Joseph Stockdale, 2014: 192).

Di Desa Ciulu Kecamatan Banjarsari Kabupaten Ciamis Jawa Barat terdapat potensi kesenian tradisional Ronggeng Gunung yang apabila di olah sedemikian rupa, maka akan menjadi daya tarik bagi turis lokal maupun non

\footnotetext{
${ }^{1}$ Penulis Koresponden

E-mail address: dewiratih@unigal.ac.id

doi: http://dx.doi.org/10.25157/ja.v4i2.909
} 
lokal. Namun sayangnya tidak ada perhatian dari pihak pemerintah. Bahkan jauh ketinggalan dengan Kabupaten Pangandaran yang sudah bergerak cepat dalam melestarikan dan melakukan kegiatan-kegiatan festifal, diantaranya festifal Ronggeng Gunung, festifal Ronggeng Amen dan festifal Angklung.

Usaha ini merupakan wadah yang efektif untuk menekan masyarakat daerah melakukan urbanisasi ke kota-kota besar sekedar untuk menjadi buruh dibandingkan untuk membangun desanya sendiri. Dengan adanya potensi kesenian tradisional ronggeng gunung, ini merupakan aset pemerintahan daerah dalam meningkatkan pendapatan daerah maupun meningkatkan pendapatan masyarakat prasejahtera.

Namun segala sesuatunya tidak dapat berjalan sendiri-sendiri. Maksudnya adalah harus ada campur tangan pemerintah dalam mensosialisasikan kesenian tradisional Ronggeng Gunung ini ke khalayak ramai. Salah satunya dengan pementasan kesenian ini pada acara-acara hajatan pemerintahan seperti pada acara hari jadi Kabupaten Ciamis, pada hari jadi Kecamatan-kecamatan se-Kabupaten Ciamis, bahkan hari jadi Desa Ciulu itu sendiri. Selain itu juga pemerintahan dalam hal ini dinas kebudayaan dan pariwisata dapat bekerjasama untuk mengadakan festifal Ronggeng Gunung.

Dengan adanya usaha-usaha tersebut tidak menutup kemungkinan akan berdampak baik untuk para seniman Ronggeng Gunung.

\section{METODE PENELITIAN}

Berdasarkan konteks permasalahan dalam penelitian ini maka bentuk penelitian yang dipilih adalah penelitian kualitatif deskriptif. Penelitian deskriptif dirancang untuk memperoleh informasi tentang status gejala saat penelitian dilakukan. Tujuan penelitian ini adalah untuk melukiskan variabel atau kondisi "apa yang ada" dalam suatu situasi (Furchan, 2011: 447). Berdasar dari tujuan penelitian, jenis penelitian ini adalah penelitian dasar (basic research). Menurut Gay dalam Sugiyono, penelitian dasar bertujuan untuk mengembangkan teori dan tidak memperhatikan kegunaan langsung yang bersifat praktis (Sugiyono, 2013: 4).

Sesuai dengan bentuk penelitian kualitatif dan jenis sumber data yang dimanfaatkan, maka teknik pengumpulan data yang digunakan dalam penelitian ini (Sugiyono, 2013: 241) adalah:
1. Observasi berperan serta (participan observation)

2. Wawancara secara mendalam (in depth interview)

3. Content analysis (Analisis Dokumen)

4. Triangulasi.

\section{HASIL PENELITIAN DAN PEMBAHASAN}

\section{Potensi Sosial Budaya Kesenian Tradisional Ronggeng Gunung Di Desa Ciulu Kecamatan Banjarsari}

\section{Perkembangan Ronggeng Gunung}

Perkembangan Ronggeng Gunung dari tahun 1940-1950an, tidak begitu berkembang diakibatkan dari banyaknya kesenian luar yang masuk ke dalam negeri diantaranya adalah; kesenian sandiwara/ theater dan film. Namun pada tahun 1948 terdapat perubahan nama pada ronggeng yaitu menjadi sinden. Hal ini dimaksudkan agar bisa merubah kesan negatif yang selama ini melekat pada diri ronggeng. Namun tetap saja kesan negatif pada diri ronggeng tidak dapat dihindarkan, karena seorang ronggeng akan melakukan apa saja asalkan kebutuhan financial mereka tercukupi (Alrianingrum, 2016: 851).

Di tahun 1950an menurut Septina kesenian ronggeng mengalami perkembangan. Para bangsawan sudah mulai melirik kesenian ini. Namun untuk perempuan bangsawan dilarang untuk menyaksikannya, karena mareka tidak mau disamakan derajatnya dengan perempuan penari ronggeng. Pada tahun 1953 kesenian ronggeng dilarang oleh pemerintah, karena dianggap hiburan yang dapat mendatangkan keonaran. Maka para ronggeng mengubah pertunjukkannya menjadi Kliningan Bajidoran. Dan Kliningan ini berkembang menjadi Kliningan Bajidoran di tahun 1963. Hal ini semakin membuat ronggeng menjadi lebih negatif dimata masyarakat. Karena mereka (sinden) melakukan tarian-tarian jaipongan dengan para penari laki-laki sambil membawakan lagu kliningan. Dalam melakukan tarian-tarian tidak jarang para penari bajidor merayu para laki-laki yang sadang menari untuk mengeluarkan uang. Hal seperti inilah yang mengakibatkan para penari ronggeng atau bajidor dianggap hina oleh masyarakat luas (Alrianingrum, 2016: 852). 
Dewi Ratih, Wulan Sondarika

Analisis Potensi Desa Ditinjau Dari Sosial Budaya Kesenian Tradisional Ronggeng Gunung

Dalam Meningkatkan Pendapatan Masyarakat Prasejahtera

(Studi kasus di desa Ciulu Kec. Banjarsari Kab. Ciamis Jawa Barat)

\section{Fungsi Ronggeng Sebagai Ritual dan Hiburan}

Seiring berjalannya waktu, kesenian ronggeng gunung ini beralih menjadi dua fungsi, yaitu sebagai tarian ritual dan hiburan. Dalam tarian ritual, ronggeng ini merupakan simbol dewi kesuburan (Dewi Sri), tetapi dalam hiburan, ronggeng merupakan penari penyemarak. ronggeng sebagai ritual akan sangat dihormati dibandingkan dengan ronggeng sebagai penghibur. Diperkirakan alih fungsi ini terjadi ketika orang Belanda mulai membuka perkebunan.

Seperti yang dijelaskan oleh (Mufidah, 2016: 848) bahwa sebagai sarana hiburan tidak jelas kapan terjadinya pergeseran fungsii ronggeng yang berperan sebagai media perantara dalam setiap upacara ritual yang selama ini dianggap sebagai perempuan yang mulia dan terhormat di mata masyarakat menjadi sebuah pertunjukan atau sebuah tontonan, bahkan kedudukannyapun berubah menjadi perempuan yang dipandang hina dan berkonotasi negative bahkan hanya dianggap sebatas penyemarak hiburan saja. Kemunculan ronggeng sebagai suatu seni pertunjukan dimulai pada masa hadirnya kebudayaan modern dalam masyarakat dengan berkembangnya perkebunan yang berkembnag dengan merekrut para tenaga kulikuli kontrak serta para perempuan-perempuan pribumi di perkebunan-perkebunan miliki pemerintah barat pada masa itu, hal ini mendorong kebudayaan barat sebagai budaya modrn ikut berkembang ditengah-tengah masyarakat Indonesia.

\section{Ronggeng Gunung Ciamis}

Di tanah Priangan Timur terdapat satu legend atau tokoh Ronggeng Gunung yaitu $\mathrm{Bi}$ Raspi. Bi Raspi merupakan sosok wanita yang sangat menjaga warisan nenek moyangnya. Bi Raspi merupakan Tokoh Ronggeng Gunung yang cukup dikenal di tanah Sunda. Beliau merupakan perempuan yang sudah berumur agak lanjut usian sudah menginjak 60 tahun, tetapi mempunyai kemampuan yang sangat mengagumkan dalam hal tarik suara. Dia bertugas membawakan lagu-lagu tertentu yang tidak dapat dibawakan oleh pesinden biasa. Awalnya dia diwarisi oleh ua Majakebun sekitar tahun 1972 ketika Bi Raspi menyelesaikan sekolah dasarnya. Awalnya antara senang dan takut. Senangnya karena malam itu dia akan tampil pertama kalinya sebagai kembang bale alias Ronggeng Gunung yang sejak lama dicitacitakannya. Sedangkan disisi lain hatinya merasa cemas, karena takut tidak bisa tampil dengan baik. Sebagai murid yang paling muda, Raspi sebenarnya merasa belum siap untuk tampil, namun seorang warga Ciganjeng telah meminangnya (menanggap) untuk tampil diacara hajatan keluarga. Dan itu adalah penghormatan yang tidak mungkin ditolak (wawancara dengan Bi Raspi tanggal 10 Januari 2018).

Sudah dijelaskan diatas bahwasannya seorang Ronggeng Gunung amat sangat disakralkan oleh khalayak banyak. Akhirnya berkat sugesti dan dorongan spiritual dari gurunya, bi Raspi tampil percaya diri. Dan malam itu, di Pakalangan hajat Raspi muda mulai ngahaleuangkeun atau membawakan 16 lagu sakral ciptaan Dewi Siti Samboja tanpa ragu. Kerja kerasnya tidak sia-sia, siang malam selama 8 hari penuh Raspi muda berlatih keras pada uwa Majakabun dan indung Dawis, tetua dan sesepuh ronggeng kahot di Gontelan. Dan malam itu pula menjadi titik awal bagi karir Raspi, yang akan mengantarkannya menjadi seorang maestro Ronggeng Gunung dari desa Ciulu kecamatan banjarsari kabupaten ciamis (wawancara dengan Bi Raspi, tanggal 10 Januari 2018).

Peristiwa pengalaman pertama yang terjadi tahun 1972 itu masih diingatnya dengan baik. 41 tahun lamanya Raspi bergelut dengan kesenian tradisi yang telah mengukuhkan namanya. Tidak saja bagi dirinya, namun juga bagi tanah kelahirannya turut diharumkan. Dedikasi wanita ini rasanya tak perlu disangsikan lagi. Dari manggung dikampungkampung sampai akhirnya di tahun 2013 Raspi dapat tampil di Singapura sebagai duta budaya indonesia, hal itu menjadi bukti bahwa Raspi dan seni Ronggeng Gunung Ciamis telah mendapat tempat terhormat di dunia seni (majalah badar. Edisi pertama. No 1/thn 1/des2013).

Sebagai catatan, untuk menjadi seorang ronggeng pada zaman dahulu memang tidak semudah sekarang. Beberapa syarat yang harus dipenuhi antara lain bentuk badan bagus, dapat melakukan puasa 40 hari yang setiap berbuka puasa hanya diperkenankan makan pisang raja dua buah, latihan nafas untuk memperbaiki suara, fisik dan juga rohani yang dibimbing oleh ahlinya. Dan, yang umum berlaku, seorang Ronggeng harus tidak terikat perkawinan. Oleh karena itu, seorang penari Ronggeng harus 
seorang gadis atau janda (wawancara dengan $\mathrm{Bi}$ Raspi tanggal 10 Januari 2018).

Kesenian Ronggeng Gunung bi Raspi yang bertempat di Desa Ciulu Kecamatan Banjarsari Kabupaten Ciamis merupakan satusatunya kesenian Ronggeng Gunung asli yang ada dan telah mewarisi kesenian ini secara turun temurun.

Sampai sekarang dia masih aktif diundang untuk perhelatan-perhelatan budaya di kotakota. Biasanya Bi Raspi dibawa keliling kota dalam perhelatan budaya yang disponsori oleh salah satu merk rokok terkenal di Indonesia. Yaitu pada tahun 2013 bi Raspi manggung di beberapa kota besar di Jawa Barat bahkan sampai Go Internasional ke Singapura yaitu pada bulan Oktober 2013. Kota-kota yang di datangi bi Raspi di daerah Jawa Barat pada tahun 2013 dalam acara "ngaronggeng" antara lain Cianjur, Manonojaya, Cikajang, Garut, Cicalengka, Cibaduyut, Purwakarta, Kuningan dan Kawali. Sedangkan peralatan musik yang digunakan untuk mengiringi tari Ronggeng Gunung adalah tiga buah ketuk, yaitu kendang, kenong dan goong (wawancara dengan bi Raspi tanggal 10 Januari 2018).

Untuk melestarikan seni budaya Sunda khususnya Ronggeng Gunung di Ciamis bagian selatan, sedikitnya ada tiga sebutan untuk pertunjukkan ronggeng: Ronggeng Gunung, Ronggeng Tayub dan Ronggeng Kaler. Masingmasing nama itu sekaligus dapat membedakan bentuk pertunjukkan masing-masing. Bentuk pertunjukkan Ronggeng Kaler (kaler = utara) merupakan pengembangan dari Ronggeng Gunung. Ronggengnya ada dua orang dan musik pengiringnya seperangkat gamelan lengkap dengan lagu-lagu kliningan. Sedangkan penyajian Ronggeng Tayub mirip dengan pertunjukkan tayub di daerah Priangan lainnya. Kedua pertunjukkan ini hanya dipergelarkan untuk hiburan dalam kenduri perkawinan dan khitanan (Dadan wildan dkk. 2005, Kab. Ciamis dalam perspektif sejarah: 131).

\section{Pengaruh Kesenian Ronggeng Gunung Terhadap Pendapatan Masyarakat Prasejahtera}

Dalam upaya mencapai sinergi pembangunan yang diinginkan maka ada beberapa aturan dan ketentuan yang harus terpenuhi dan dipenuhi. Sesuai dengan tujuan pembangunan kabinet kerja pada pemerintahan saat ini maka ketentuan dan aturan yang harus dipenuhi menyangkut norma, dimensi Tujuan utama dalam pembangunan ini adalah memperkuat daerah atau desa untuk mempercepat pertumbuhan dan pemerataan (Soleh, 2017: 43).

Dari kutipan diatas bahwa masyarakat dapat mewujudkan keinginannya untuk hidup berkecukupan dengan mengendalikan kemampuan ( skill) yang dimiliki, sehingga peran partisipasi yang aktif dan kreatif sangat berperan serta guna meningkatkan perekonomian pribadi dan perekonomian desanya. Potensi Desa bukan hanya terletak pada Sumber Daya Alam dan Usaha Kecil Menengah saja melainkan dapat digali melalui keahlian lain, seperti dapat ditinjau dari potensi sosial budaya, baik itu dari kesenian tradisional maupun dari acara ritualritual Desa. Dari kekreatifitasan yang lain ini, tidak menutup kemungkinan desa tersebut akan menjadi daya tarik turis lokal bahkan turis asing dan kemungkinan kedepannya akan tercipta kampung budaya.

Pada dasarnya di Desa Ciulu Kecamatan Banjarsari Kabupetan Ciamis terdapat potensi desa dari segi sosial budaya yaitu dengan terdapatnya pelaku kesenian tradisional Ronggeng Gunung. Apabila kesenian Ronggeng Gunung ini dapat dikembangkan, maka hal ini akan berpengaruh pada pendapatan pelakunya itu sendiri dan secara umum pada pendapatan Desa. Caranya yaitu dengan adanya peran serta dari pihak pemerintahan daerah itu sendiri seperti pada acara-acara hajatan Desa, hajatan Kecamatan, hajatan Kabupaten dan acara-acara ritual yang lain. selain itu dengan re-generasi Ronggeng Gunung terhadap anak-anak usia dini dan remaja dengan diwajibkannya latihan Ronggeng Gunung ini melalui ekstrakurikuler di sekolah PAUD, TK, SD, SMP maupun SMA.

Namun dari hasil pengumpulan data yang dilakukan peneliti ke Desa Ciulu Kecamatan Banjarsari Kabupaten Ciamis bahwasannya pengaruh Ronggeng Gunung terhadap pendapatan masyarakat prasejahtera kurang memberikan dampak baik terhadap perekonomian masyarakat terutama bagi pelaku Ronggeng Gunung itu sendiri.

Dari hasil wawancara dengan Bi Raspi tanggal 10 Januari 2018, selaku pelaku kesenian Ronggeng Gunung beliau menuturkan bahwasannya tidak ada perhatian dari pihak pemerintah terhadap kesenian Ronggeng Gunung. Hal ini sangat disayangkan oleh peneliti dikarenakan kesenian tradisional Ronggeng Gunung ini merupakan ikon Kabupaten Ciamis. Bahkan untuk sekarang ini, 
Dewi Ratih, Wulan Sondarika

Analisis Potensi Desa Ditinjau Dari Sosial Budaya Kesenian Tradisional Ronggeng Gunung

Dalam Meningkatkan Pendapatan Masyarakat Prasejahtera

(Studi kasus di desa Ciulu Kec. Banjarsari Kab. Ciamis Jawa Barat)

bi Raspi dan rombongan sering dimintai untuk manggung Ronggeng Amen yang merupakan kesenian khas dari wilayang Kuningan. Ini dikarenakan kurang adanya sosialisasi kesenian tradisional terhadap masyarakat.

Untuk menarik pasar, sebenarnya dapat dimulai dari pihak pemerintahan daerah itu sendiri dengan melakukan sosialisasi seperti mengundang pada acara-acara hajatan Desa, hajatan Kecamatan, hajatan Kabupaten dan acara-acara ritual yang lain supaya masyarakat sekitar dapat menyaksikan. Maka dengan diperkenalkannya kembali Ronggeng Gunung pada masyarakat melalui acara-acara pemerintahan, tidak menutup kemungkinan masyarakat ada yang tertarik dan meminta untuk memainkannya. Selain menambah pendapatan pada personil Ronggeng Gunung, juga dapat menambah pendapatan masyarakat setempat.

Pada dasarnya cara ini bukan hanya saja dapat memperbaiki perekonomian masyarakat, melainkan dapat melestariakan budaya asli Indonesia yang sudah mulai tergerus oleh zaman. Maka dari itu penting diadakan pelatihan-pelatihan tarian Ronggeng Gunung pada generasi muda.

\section{PENUTUP}

Ronggeng Gunung merupakan kesenian asli Jawa Barat. Kesenian tradisional ini masih di klaim oleh dua kabupaten, yaitu oleh Kabupaten Ciamis dan Kabupaten Pangandaran yang merupakan wilayah pemekaran dari Kabupaten Ciamis.

Pusat dari Ronggeng Gunung Ciamis yaitu berada di Desa Ciulu Kecamatan Banjasari yang tokohnya adala $\mathrm{Bi}$ Raspi dengan nama sanggarnya yaitu Panggugah Rasa.

Ronggeng Gunung juga merupakan potensi desa yang bisa di kembangkan untuk menambah pendapatan masyarakat prasejahtera.

Namun sayangnya kesenian tradisional ini tidak ada perhatian dari pemerintah. Baik itu pemerintah daerah maupun dari pemerintah pusat. Sehingga para pelaku seni Ronggeng Gunung berbanting setir pada Ronggeng Amen.

Dituturkan oleh Bi Raspi selaku pelaku kesenian Ronggeng Gunung, bahwasannya pihak pemerintahan Kabupaten Ciamis belum pernah mengundang beliau tampil dalam acara hari jadi Kabupaten Ciamis. Hal ini sangat disayangkan peneliti. Karena apabila tidak dimulai di sosialisasi oleh pemerintah, maka kesenian asli Ronggeng Gunung ini akan hilang.

\section{DAFTAR PUSTAKA}

Alrianingrum, Septina. 2016. AVATARA. Surabaya: e-Journal Pendidikan Sejarah Volume 4, No. 3, Oktober 2016

Majalah Badar No 1/THN I/ Des. 2013. Aset Macet Pemda Ciamis. LSM Badar. Ciamis

Mufidah. 2016. Pengaruh Pembelajaran Etnomatematika Sunda Terhadap Kemampuan Penalaran Siswa Sekolah Dasar. Bandung: Skripsi Mahasiswa UPI

Soleh, Ahmad. 2017. Strategi Pengembangan Potensi Desa. Bandung: Jurnal Sungkai Vol.5 No.1, Edisi Februari 2017

Stockdale, John Joseph. 2014. The Island of Java Sejarah Tanah Jawa. Yogyakarta. Indonesia.

Sugiyono. 2013. Metode Penelitian Kuantitatif, Kualitatif, dan R\&D. Bandung: Alfabeta.

Wildan, Dadan. 2005. Kabupaten Ciamis dalam Perspektif Sejah. Pemerintah Kab. Ciamis bekerjasama dengan LPPM Universitas Galuh Ciamis. Ciamis. 
Jurnal Artefak:

History and Education, Vol.4 No.2 September 2017

Halaman | 166 